\title{
A System Dynamics based Simulation Study for Managing Clinical Governance and Pathways in a Hospital
}

\author{
Mahendran Maliapen and Brian Dangerfield
}

\begin{abstract}
This paper examines the development of clinical pathways in a hospital in Australia based on empirical clinical data of patient episodes. A system dynamics (SD)-based decision support system is developed and analyzed for this purpose. The study highlights the scenarios that will help hospital administrators to redistribute caseloads amongst admitting clinicians with a focus on multiple Diagnostic Related Groups (DRG's) as the means to improve the patient turnaround and hospital throughput without compromising quality patient care. DRG's are the best known classification system used in a casemix funding model. Casemix is a DRG-based government funding model for hospitals with a mix of performance measures aiming to reward initiatives that increase efficiencies in hospitals. The classification system groups inpatient stays into clinically meaningful categories of similar levels of complexity that consume similar amounts of resources. Policy explorations reveal various combinations of the dominant policies that hospital management can adopt. With the use of visual interfaces, executives can manipulate the DSS to test various scenarios. Experimental evidence based on focus groups demonstrated that it can enhance group learning processes and improve decision making. The findings are supported by other recent studies of clinical pathway implementation on various DRG's. These showed substantial reduction in length of stay, costs and resource utilization.
\end{abstract}

Running Head: "System Dynamics Study for Clinical Pathways in a Hospital”

Keywords: Clinical Pathways (CP), System Dynamics (SD), Decision Support System (DSS), Diagnostic Related Groups (DRG)

\section{Introduction}

The techniques associated with the traditional hospital turnaround - although still important - are not sufficient for achieving and sustaining positive performance. These results are usually symptomatic of multiple problems throughout the organization, such as weak or dysfunctional management, failed or inadequate medical staff strategies, uncompetitive costs, weakened market position, or failed strategies. Cost reduction policies produce such phenomena directly because of loss of staff and decreased efficacy of care, and indirectly when these problems cause loss of patient population and overall higher per capita costs. A simulation approach offers hospital policy makers a hands-on way to experience a number of these archetypal phenomena.

The study described was based upon work with Australian data. Here the notions of "profit" and "markets" are not uncommon and this contrasts somewhat with a publicly-financed system, free at the point of use, such as is found in the National Health Service in the United Kingdom.

Historically, most of the solutions to hospital turnarounds can be found within the institution itself. By initiating dramatic cuts in expenses, involving clinicians, maximizing revenue and cash flow, attempting to increase volume, improving market position, and other "tried-and-true" techniques, hospitals can turn themselves around and maintain profitability.

The key trends identified in this research study point to declining in-patient utilization and revenues with average hospital occupancy of less than $60 \%$. The hospital is therefore carrying debt for beds that are not being used. Many hospital boards have been caught by surprise because they did not understand how fast patient days and revenue could decrease in their market, or because volume assumptions were just wishful thinking, not supported by market realities or even the hospital's own trends. 
One of the key strategic business decisions in a hospital, that could significantly alter the trajectory of the hospital towards "best clinical practices" and healthy surpluses, is the establishment of a Clinical Pathways (CP) Policy. Clinical Pathways describes the usual way of providing multidisciplinary care for a particular type of patient and allows annotation of deviations from the norm for the purpose of improvement (Hindle, 1998). The Australian Health Legislation Act also requires contracts between health funds and hospitals to be described on the basis of the Australian National Diagnostic Related Groups. This enables hospital managers to undertake medical treatment costs variance analysis.

Clinical pathways can provide reasons for variance and empower management to redress the system. Analysis of individual clinician variance could possibly result in suggestions for changes in care, economic punitive action (such as withdrawal of accreditation), or demands that a clinical pathway be adhered to as a condition of future accreditation or agreement between clinician and hospital. With a system dynamics (SD)-based simulation model (Sterman, 2000), it is possible to understand the "most cost effective clinical practice" within the hospital for a particular DRG profiled against the national benchmarks for that DRG.

\section{Literature}

Medical research findings are slow to change medical opinion and practice (Phillips, 1998). Empirical studies have shown that on average, there is an 8-13 year time lag (depending on the specialty) between a treatment being proven to work and its adoption as standard practice. It has also been found that $70 \%$ of treatments currently in use do not have sufficient evidence to support that they are any more effective than doing nothing (Chalmers, 1993). One of the major barriers to the implementation of research findings is the volume and geometric growth of the medical literature. It is not humanly possible to keep up with all the advances in all areas of medical research (Jordens et al, 1998). It is also difficult for medical practitioners to make sense of the often-conflicting research findings in a particular area.

Recognition of such problems led to the discipline of evidence based medicine (EBM). The aim of EBM is to bring research and practice closer together and reduce the time lag between the development of clinically proven treatments and their use in everyday medical practice as clinical pathways.

The medical profession's approach to unexplained clinical variation in treatment practices understandably leads to the undesirable side effect of cost increases. The hospital executives involved in this research study explained that the introduction of clinical pathways as practice guidelines in some DRG's would reduce by $30 \%$ percent the variation in clinician practice patterns for cases without clinical complications or comorbidities. The clinical variance for 1998 in the hospital under study was estimated at 200\%. Emerging literature on clinical pathways shows how their use contributes to improving the appropriateness and integration of care and its outcomes, lowering complication and infection rates, improving patient participation and satisfaction and achieving better resource utilization (Ellrodt et al. 1995; Holt et al. 1996; Leape, 1990; Lomas, 1989; Thomson et al 1995).

Studies in the University of Pennsylvania Health System (Guadagnino, 1998) which implemented 30 clinical pathways (for conditions such as hysterectomy, asthma, bone marrow transplant, carotid endarterectomy, colectomy, craniotomy, cystic fibrosis, gastro-intestinal bleed, hip and knee replacement, low birth weight infants, pneumonia and liver transplants) found that clinician resistance and collection of variance information vis-à-vis the pathways were formidable issues.

\section{Model Structure \& Development}

Five hospital focus group members were actively involved in the model development process. The focus group, which included two clinicians, helped the author to identify the key trails in the flows of patients and monetary transactions taking a "process-orientated" view through the organization (Vissers and Beech, 2005). In order to understand hospital throughput and contributing drivers to workload it is necessary to understand the linkages between patient referrals, clinician interactions, hospital performance and costs. A visual walkthrough of the business processes was also conducted. A more complex model was developed 
during the workshops for the Clinician \& Patient Market, Clinical Governance, Financial Management and Hospital Management domains.

The knowledge elicited and relationships between the players are identified in figures 1 and 2 below (Maliapen, 1998a). Table 1 provides the details of these identified relationships as linkage vectors indicating the reinforcing (S-same direction) or opposing (O-opposite direction) behavior. In figure 1 information linkages are illustrated as dotted lines in the dynamic hypotheses and delays in response to actions have been indicated where appropriate. Linkages with continuous black lines indicate the flow of resources such as cash or patients within the organization (also figure 1). As regards figure 2 the bolder continuous loops indicate the existence of feedback loops and these are labeled (B) for balancing loops and (R) for reinforcing loops. The relationships in model structure were developed based upon the experience of hospital professionals, researched literature references and evidence of documented hospital practices.

Despite clinicians' consternations, the hospital's efforts to standardize clinical practices have gradually intensified over the last few years. There were 7372 inpatient admissions spread across 13 DRG's and casemix data analysis showed that in at least eight of these DRG's there were 30 or more different clinicians involved per DRG over the year. Workshop participants agreed that the volume of cases treated per clinician and the associated DRG's per Clinician was low. The number of adjacent DRG's treated in the same specialty; in $43 \%$ of the cases analyzed were only 2 per clinician while $40 \%$ of clinicians treated single DRG's. Both these factors were considered to significantly impact the level of entropy and dispersion in the hospital system with 13 DRG's being treated by 132 clinicians (Table 1, link 4 \& 7).

Participants stated that the range of DRG's and the volume of cases treated per clinician at the hospital had a tremendous impact on the services contribution of the clinician to the hospital. The services contribution is numerically equivalent to the product of the cost weight and the clinician caseload for each DRG. Under the casemix system, hospitals are paid for treatment to patients based on the cost weight which is the relative time each patient stays in hospital compared to other patients with similar conditions and the relative cost of treating their condition compared to the cost of other illnesses. In general, hospital management tends to regard revenue contributions from "high volume" DRG clinicians as "sustainable income streams" and critical to the hospital financial position. Hospital management tend to balance the reluctance of clinicians towards "performance measurement", much needed for clinical pathways, with measures to retain their services through incentives and higher satisfaction levels. Participants mentioned that attrition of these clinicians would erode their profit margins hence a desire to reduce low volume clinicians is important (Table 1, link 6).

Clinical governance in acute care settings is a further indication of the increasing concern about clinician accountability and about efficiency and effectiveness of hospitals as the core units of the health care system (Secretary of Health, 1997; Scally and Donaldson, 1998; Lugon and Secker-Walker, 1999). The twin aims of improving clinical effectiveness and hospital efficiency are interpreted as signaling a substantial extension of management into clinical preserves, particularly in respect of resource use implications of clinical practice and the profession's claimed right to self -regulation.

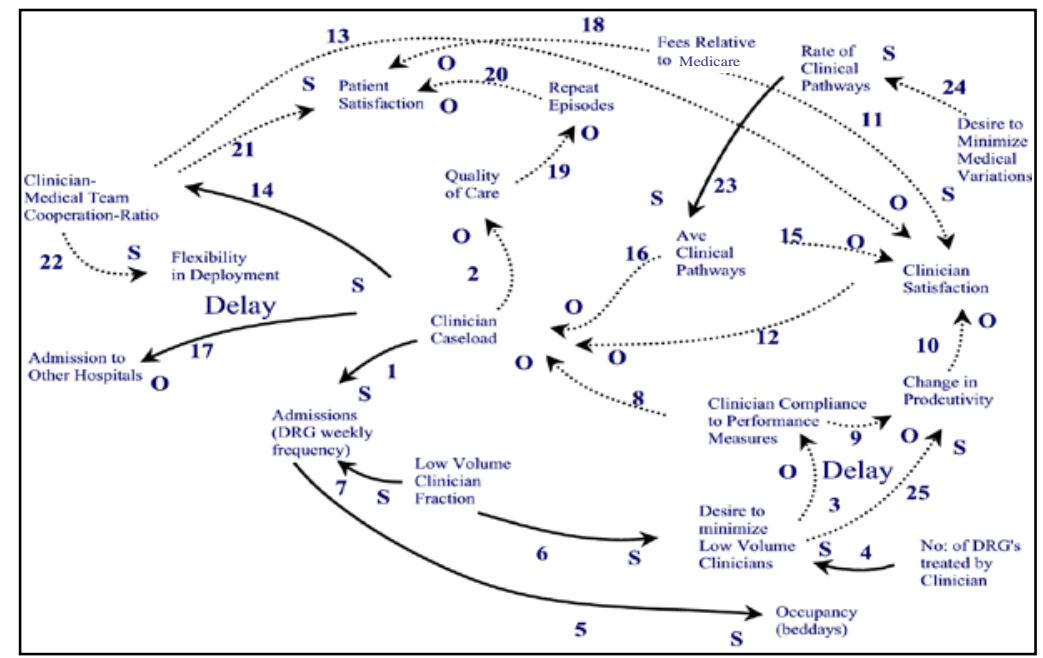


Figure 1: SD Model Structure for Clinical Governance

Pathways could speed up treatment regimens by flagging therapies at appropriate intervals and including drug plans that rein in costs (e.g. brands of medication or prostheses) attributed to discretionary prescription habits across clinicians (Table 1, link 24). The issues of clinician compliance to performance measurement and clinician satisfaction are interdependent (Table 1, links 8 \& 15). Hospital executives suggested that better compliance behavior can be achieved with the use of education, clinical opinion leaders, peer review, feedback of patient data, administrative interventions and incentives (both financial and non financial). Of these, literature review supports the financial incentives as the most effective tool to achieve compliance behavior. (Table 1, link 14) (Dickinson et. al.,1999).

Given that the average length of stay for each DRG remains unchanged, then as the volume of hospital admissions increases, the bed occupancy of the hospital rises. As a workload driver, increased bed occupancy increases the workload of clinicians, the hospital's nursing and medical staff but inadvertently reduces their span of attention per patient. The possibility of lengthening the patient's hospital stay to cope with the increasing workload is a natural side effect to improve treatment. The resulting quality of care has an impact on patient satisfaction. An adverse level in the quality of care over many patients has a delayed effect on clinician referrals and consequently impacts the clinician's future caseload.

Medical and nursing staffing mix will determine the clinician/medical team staff ratio and co-operation levels (Table 1, link 14). With higher case volumes (link 22) and movement in staff rosters, shifting workload demands affect the availability of staff for better patient care management, which consequently impacts the quality of care and patient satisfaction during the hospital stay. The clinician's reputation and experience naturally determines his command of the market share, not to mention that the skills for treating multiple DRG's will increase demand for the clinician's services.

Table 1: Clinical Governance Loops and Links

\begin{tabular}{|c|c|c|c|c|}
\hline \multirow[t]{2}{*}{ Links } & \multirow{2}{*}{$\begin{array}{l}\text { Vector } \\
\text { (S/O) }\end{array}$} & \multicolumn{2}{|l|}{ Linkage Description } & \multirow[t]{2}{*}{ Comments } \\
\hline & & $\begin{array}{l}\text { Input Link } \\
\text { Link }\end{array}$ & Output & \\
\hline 1 & $S$ & $\begin{array}{l}\text { Hospital Clinician } \\
\text { Caseload }\end{array}$ & $\begin{array}{l}\text { Hospital } \\
\text { Admissions }\end{array}$ & \\
\hline 2 & $\mathrm{O}$ & $\begin{array}{l}\text { Hospital Clinician } \\
\text { Caseload }\end{array}$ & $\begin{array}{l}\text { Clinician } \\
\text { Quality of Care }\end{array}$ & Information Link \\
\hline 3 & $\mathrm{O}$ & $\begin{array}{l}\text { Desire to minimize } \\
\text { Low Volume } \\
\text { Clinicians }\end{array}$ & $\begin{array}{l}\text { Clinician } \\
\text { Compliance to } \\
\text { Performance } \\
\text { Measures }\end{array}$ & $\begin{array}{l}\text { Information Link \& } \\
\text { Delay }\end{array}$ \\
\hline 4 & S & $\begin{array}{l}\text { No of DRG's } \\
\text { treated by } \\
\text { Clinician }\end{array}$ & $\begin{array}{l}\text { Desire to } \\
\text { minimize Low } \\
\text { Volume } \\
\text { Clinicians } \\
\end{array}$ & \\
\hline 5 & $S$ & $\begin{array}{l}\text { Hospital } \\
\text { Admissions }\end{array}$ & Occupancy & \\
\hline 6 & $S$ & $\begin{array}{l}\text { Low Volume } \\
\text { Clinician Fraction }\end{array}$ & $\begin{array}{l}\text { Desire to } \\
\text { minimize Low } \\
\text { Volume } \\
\text { Clinicians } \\
\end{array}$ & \\
\hline 7 & $S$ & $\begin{array}{l}\text { Hospital } \\
\text { Admissions }\end{array}$ & $\begin{array}{l}\text { Low Volume } \\
\text { Clinician } \\
\text { Fraction } \\
\end{array}$ & \\
\hline 8 & $\mathrm{O}$ & $\begin{array}{l}\text { Clinician } \\
\text { Compliance to } \\
\text { Performance } \\
\text { Measures }\end{array}$ & $\begin{array}{l}\text { Hospital } \\
\text { Clinician } \\
\text { Caseload }\end{array}$ & Information Link \\
\hline
\end{tabular}




\begin{tabular}{|c|c|c|c|c|}
\hline \multirow[t]{2}{*}{ Links } & \multirow{2}{*}{$\begin{array}{l}\text { Vector } \\
\text { (S/O) }\end{array}$} & \multicolumn{2}{|l|}{ Linkage Description } & \multirow[t]{2}{*}{ Comments } \\
\hline & & $\begin{array}{l}\text { Input Link } \\
\text { Link }\end{array}$ & Output & \\
\hline 9 & $\mathrm{~S}$ & $\begin{array}{l}\text { Clinician } \\
\text { Compliance to } \\
\text { Performance } \\
\text { Measures }\end{array}$ & $\begin{array}{l}\text { Change in } \\
\text { Productivity }\end{array}$ & Information Link \\
\hline 10 & $\mathrm{O}$ & $\begin{array}{l}\text { Change in } \\
\text { Productivity }\end{array}$ & $\begin{array}{l}\text { Clinician } \\
\text { Satisfaction }\end{array}$ & Information Link \\
\hline 11 & $\mathrm{~S}$ & $\begin{array}{l}\text { Fees Relative to } \\
\text { Medicare }\end{array}$ & $\begin{array}{l}\text { Clinician } \\
\text { Satisfaction }\end{array}$ & Information Link \\
\hline 12 & $\mathrm{O}$ & $\begin{array}{l}\text { Clinician } \\
\text { Satisfaction }\end{array}$ & $\begin{array}{l}\text { Hospital } \\
\text { Clinician } \\
\text { Caseload }\end{array}$ & Information Link \\
\hline 13 & $\mathrm{O}$ & $\begin{array}{l}\text { Clinician-Hospital } \\
\text { Medical Team } \\
\text { Cooperation Ratio }\end{array}$ & $\begin{array}{l}\text { Clinician } \\
\text { Satisfaction }\end{array}$ & Information Link \\
\hline 14 & $\mathrm{~S}$ & $\begin{array}{l}\text { Hospital Clinician } \\
\text { Caseload }\end{array}$ & $\begin{array}{l}\text { Clinician- } \\
\text { Hospital } \\
\text { Medical Team } \\
\text { Cooperation } \\
\text { Ratio }\end{array}$ & \\
\hline 15 & $\mathrm{O}$ & $\begin{array}{l}\text { Ave Clinical } \\
\text { Pathways }\end{array}$ & $\begin{array}{l}\text { Clinician } \\
\text { Satisfaction }\end{array}$ & Information Link \\
\hline 16 & $\mathrm{O}$ & $\begin{array}{l}\text { Ave Clinical } \\
\text { Pathways }\end{array}$ & $\begin{array}{l}\text { Hospital } \\
\text { Clinician } \\
\text { Caseload }\end{array}$ & Information Link \\
\hline 17 & $\mathrm{O}$ & $\begin{array}{l}\text { Hospital Clinician } \\
\text { Caseload }\end{array}$ & $\begin{array}{l}\text { Proportion of } \\
\text { Caseload } \\
\text { Admitted to } \\
\text { Other Hospitals }\end{array}$ & \\
\hline 18 & $\mathrm{O}$ & $\begin{array}{l}\text { Fees Relative to } \\
\text { Medicare }\end{array}$ & $\begin{array}{l}\text { Patient } \\
\text { Satisfaction }\end{array}$ & Information Link \\
\hline 19 & $\mathrm{O}$ & $\begin{array}{l}\text { Clinician Quality } \\
\text { of Care }\end{array}$ & $\begin{array}{l}\text { Repeat } \\
\text { Episodes }\end{array}$ & Information Link \\
\hline 20 & $\mathrm{O}$ & Repeat Episodes & $\begin{array}{l}\text { Patient } \\
\text { Satisfaction }\end{array}$ & Information Link \\
\hline 21 & $\mathrm{~S}$ & $\begin{array}{l}\text { Clinician-Hospital } \\
\text { Medical Team Co- } \\
\text { operation Ratio }\end{array}$ & $\begin{array}{l}\text { Patient } \\
\text { Satisfaction }\end{array}$ & Information Link \\
\hline 22 & $S$ & $\begin{array}{l}\text { Clinician-Hospital } \\
\text { Medical Team Co- } \\
\text { operation Ratio }\end{array}$ & $\begin{array}{l}\text { Flexibility of } \\
\text { Deployment }\end{array}$ & Information Link \\
\hline 23 & $\mathrm{~S}$ & Rate of Pathways & $\begin{array}{l}\text { Ave Clinical } \\
\text { Pathways }\end{array}$ & \\
\hline 24 & S & $\begin{array}{l}\text { Desire to minimize } \\
\text { medical variations }\end{array}$ & $\begin{array}{l}\text { Rate of Clinical } \\
\text { Pathways }\end{array}$ & \\
\hline 25 & $\mathrm{~S}$ & $\begin{array}{l}\text { Desire to minimize } \\
\text { Low Volume } \\
\text { Clinicians }\end{array}$ & $\begin{array}{l}\text { Change in } \\
\text { Productivity }\end{array}$ & \\
\hline
\end{tabular}




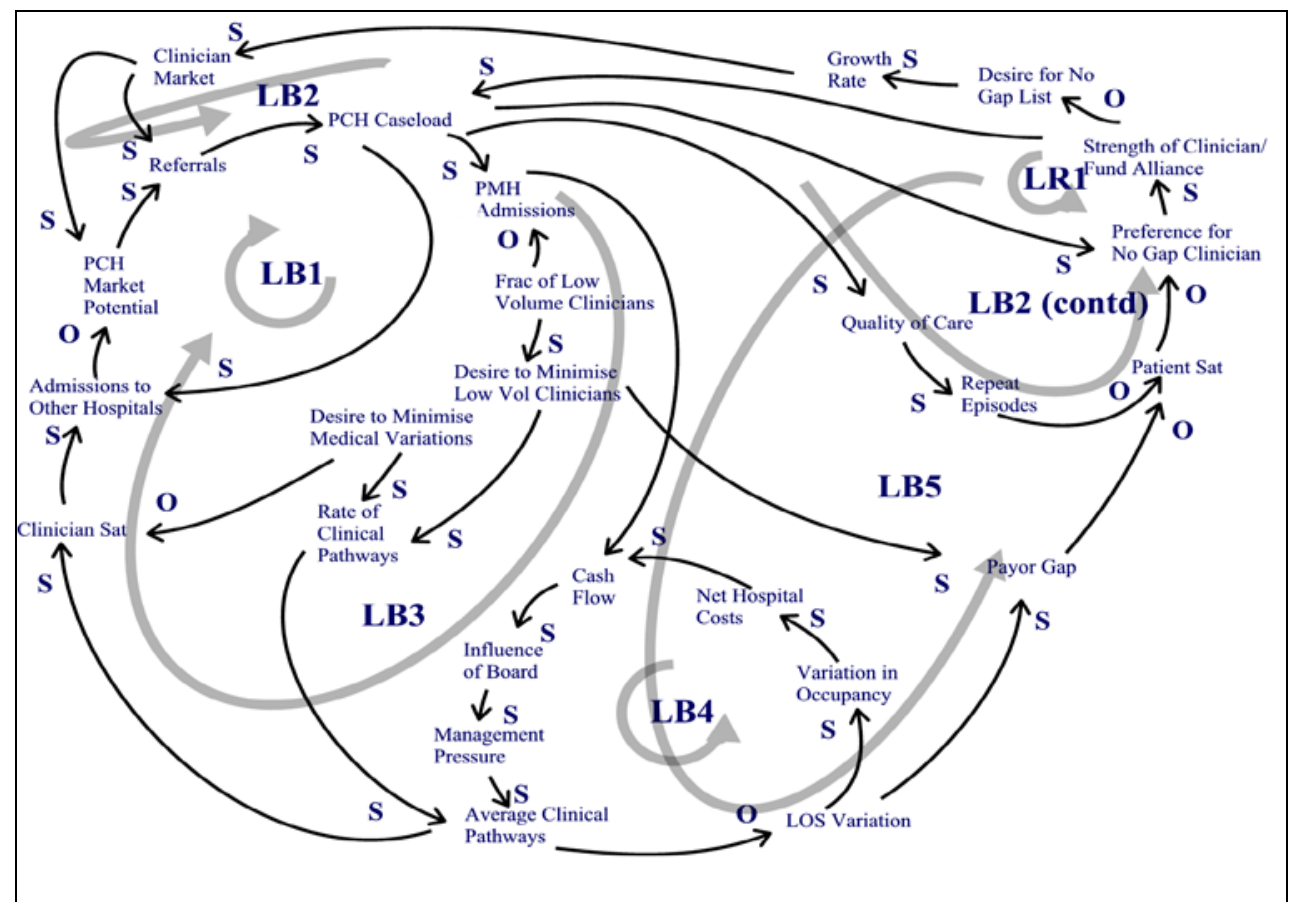

Figure 2: Causal Loop Analysis for Clinical Governance (Note: PCH \& PMH are acronyms associated with the hospital and unit involved; LOS is Length of Stay)

\section{Model Evaluation}

The study participants were interviewed to investigate their perceptions about learning and applying the SD models for decision-making. Issues investigated during interviews include: the understanding of the model design and its purpose; the value of the visual user interface to the decision maker and its contribution to understanding the model structure; the decision maker's learning curve with the visual interface (VI); the impact of the VI on decision making; the benefits and the perceived advantages of SD-based VI models.

A questionnaire, consisting of 40 questions was developed to probe hospital managers' views of SD-based VI models. The questionnaire was applied to the 5 focus group members and the 30 participants independently. All respondents were provided the questionnaires 2 weeks prior to the interviews. The focus group was regarded as the reference group of model-builders' as they are involved in all phases of model development, evaluation and analysis.

The responses were analyzed in a descriptive fashion across four dimensions namely model characteristics, manipulation, evaluation and performance. The differences between the focus group members' responses and the hospital managers' responses were determined. The similarity in the responses helped build confidence that the views of other managers within the hospital population were consonant with the views of the focus group towards SD-based VI models.

\section{Reference Mode and Baseline Model}

The reference mode was fundamental to model structure evaluation - for the purposes of discovering patterns and sensitivity analysis, simulation of multiple policies and scenarios. The model was parameterised for the situation before clinical pathways were introduced so as to provide a benchmark against which to compare the CP implementation. The model was tested against two years of historical casemix data using actual patient arrival patterns. It produced acceptable error rates in forecasting historical financial performance, bed occupancies and seven other key performance indicators. Clinicians and hospital administrators validated the model responses in the case study and compared the simulated results against the Actual Financial Performance - called the Reference Mode. 
However, it needs to be pointed out that occurrence of events in the past alone cannot be interpreted to mean that events in the future will follow accordingly. While both historical financial behavior and a reference mode can be expressed in either quantitative or descriptive terms, a reference mode is essentially a qualitative and intuitive concept since it represents a pattern rather than a precise description of a series of events (Saeed, 1998). A reference mode also subsumes past history, extended experience and a future inferred from projecting the inter-related past trends based on the experience of the experts. A reference mode will also not contain random noise normally found in historical trends, as noise represents a problem behavior rather than the system behavior. The caveat is with the exclusive use historical casemix data to construct the reference mode.

\section{Simulation Analysis \& Results}

The clinical pathways policy is also the result of hospital management's desire to reduce medical errors and deviations in clinical practice and also to reduce the number of clinicians with low case volumes. Each DRG or disease group has its own pathway documenting the details of the recommended procedures, expected patient outcomes, pharmaceuticals, clinical investigations, prognosis monitoring and instrumentation for the surgical procedure. The formalization of pathways in any hospital environment is tedious and a challenging implementation which requires many hours of education, protocol explanation, monitoring and control against targets. There are benefits for such a long-term view as this clinical methodology introduces standardization in medical practice.

In the simulation results reported below the run time is 104 weeks. The two year time horizon for the simulation modeling was considered adequate and reasonable by the hospital executives and clinicians who participated in this study. The initial values of hospital costs are negative followed by a subsequent ramp up which is a fluctuation inherent in the data reflecting the volume of patients being treated at that point in time.

In the simulation model, the desire to minimize the number of clinicians with low practice volumes is management's central objective. In applying the CP policy, it was decided that patient admissions be held constant throughout the experimentation with the pathway variables such as the rate of CP implementation, the desire to minimize medical procedure deviations and the level of pathways arrayed across the DRG's. A switch in the simulation model labeled 'Clinical Governance Policy' maintains the same patient volume to allow experimentation with the effectiveness of CP policies.

One significant simulation result demonstrates (Figure 3) that hospital costs decrease with increased CP implementation. Such a policy allows a potential increase in capacity to treat more patients (described by variations in occupancy) resulting from the overall reductions in lengths of stay (due to adherence to recommended CP procedures). This is reflected in loop LB4 in figure 2. In Figure 3, Plot 3 and 4 show some oscillations. The oscillations are an indication of the hospital's dependence on a few "admitting" clinicians for DRG G45B - Gastroscopy - and seem to indicate that admission numbers fluctuated until the patients became aware that low volume clinicians no longer had admitting rights to the hospital for this DRG. It requires 18 months to arrive at a near steady upward trend. The "ramp up" of net hospital costs in the initial weeks is due to negative start-up costs in the simulation data.

The different levels of clinical pathways across the DRG's are shown in Figure 4. This graph plots the effectiveness of CP policy implementation. The qualitative linear scale of CP is from 0-1000 with no CP implemented at the zero end and full CP implemented at the upper end of the scale. It is clear that the model represents hospital management's desire to reduce clinical and treatment variances relative to the divergent number of clinicians practicing at the hospital. Clinical treatment variations from a large number of clinicians dissipate the efforts of the clinical pathways policy to streamline clinical practices. The number of practicing clinicians for DRG G45B (Gastroscopy) was reduced to test this policy. A smaller and more manageable group of clinicians with focus on implementing the $\mathrm{CP}$ system would bring better benefits to the organization. 


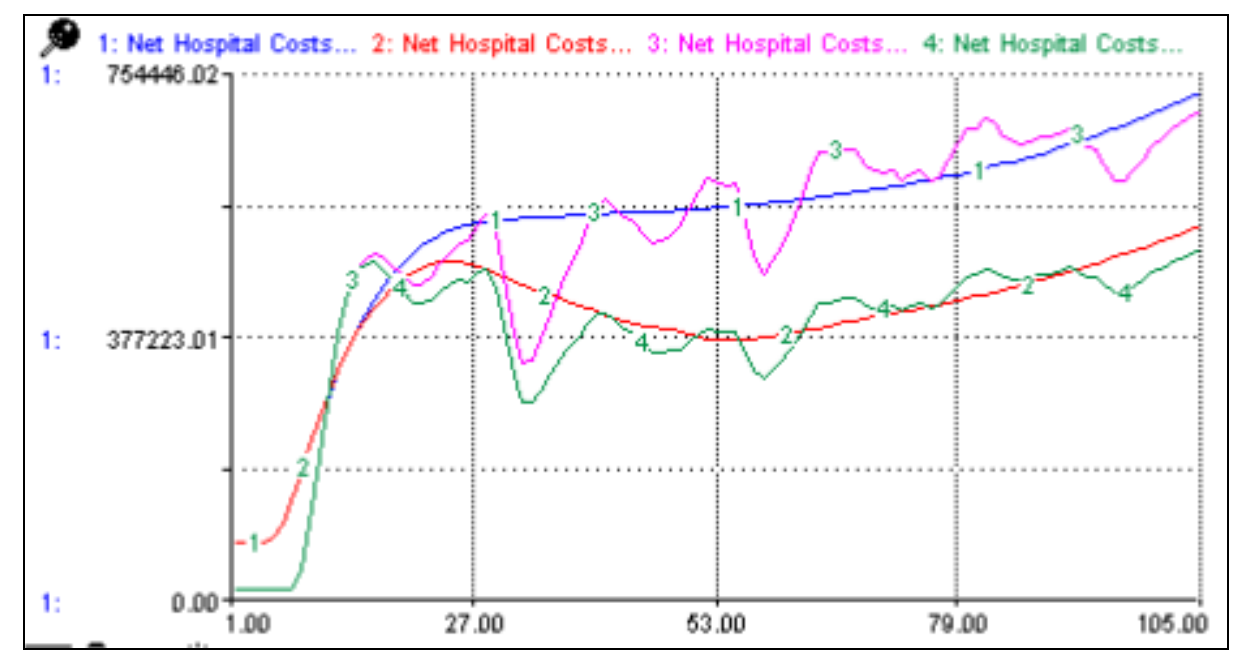

(Plot 1 - No CP implemented; Plot 2- CP implemented; Plot 3- No CP implemented but with reduction of low volume clinicians in DRG G45B; Plot 4 - CP implemented with a reduction of low volume clinicians in DRG G45B) Y-axis Net Hospital Costs in AUD\$

Figure 3: Clinical Pathways Policy - Net Hospital Costs Variation (G45B = Gastroscopy)

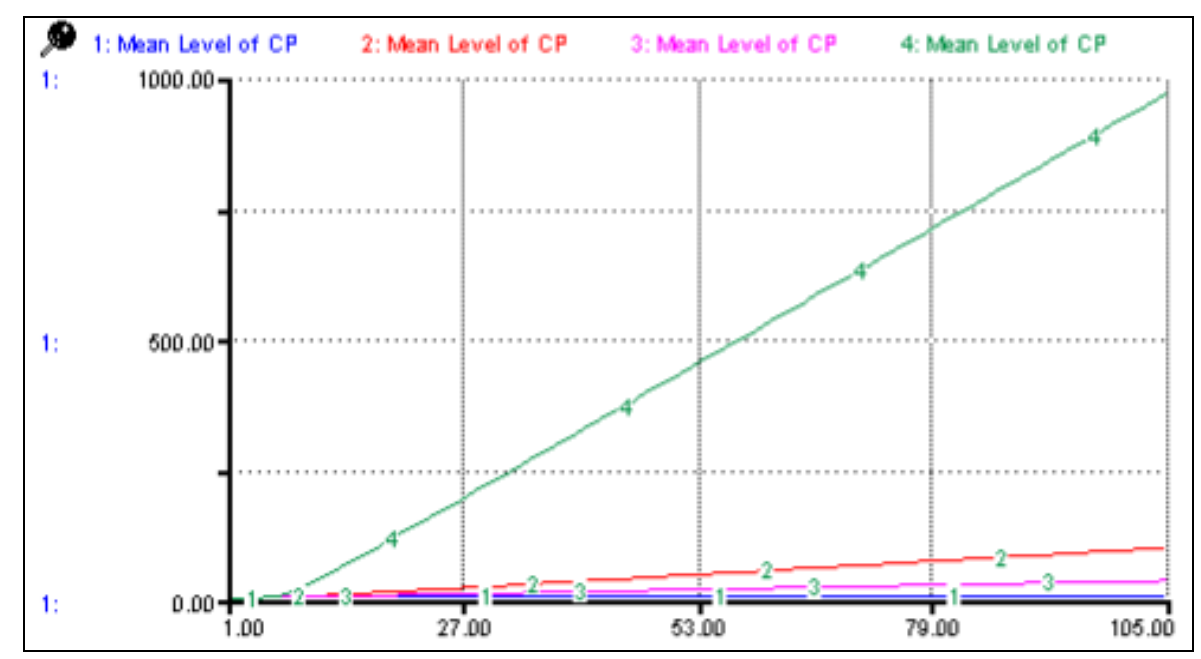

(Plot 1 - No CP implemented; Plot 2- CP implemented; Plot 3- No CP implemented but with reduction of low volume clinicians in DRG G45B; Plot 4 - CP implemented with reduction of low volume clinicians in DRG G45B) - Y-axis scale 0 - no CP implemented and 1000 - Full CP implemented

Figure 4: Clinical Pathways Policy - Mean CP Level (G45B= Gastroscopy)

It is also worth noting that the overall bed occupancy of the hospital peaked much earlier in week 79 (Figure 5; Plot 1) than, for the same volume of patients, the actual performance reported over two years. This finding reveals that the experimentation with various CP implementation strategies can lead to early saturation of capacity, simultaneously achieving operational efficiency. Hospital management indicated that, from their experience, CP implementation actually has a regulatory effect on the use of shared resources within the hospital. 


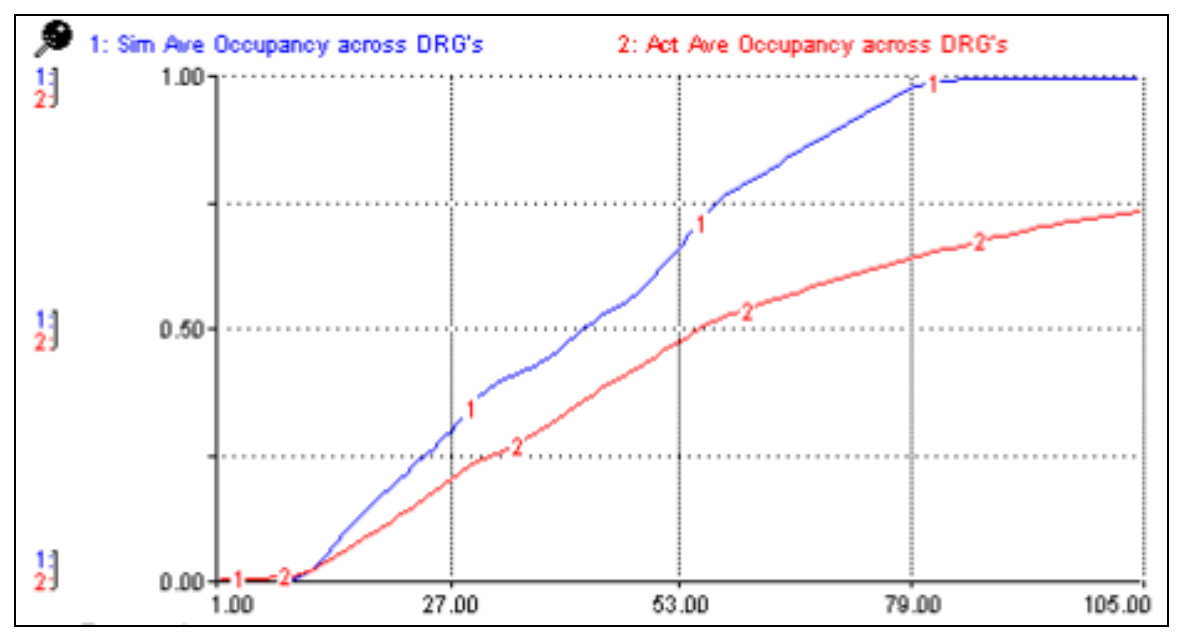

(Plot 1- Simulated Occupancy, Plot 2 - Actual Occupancy)

Figure 5: Clinical Pathways Policy - Bed Occupancy (\%)

The variations in bed occupancies enable the treatment of more patients, a side effect of overall shorter lengths of stay and more efficient clinical care. This desired effect from CP implementation is shown in Figure 6 for each of the simulations. The Sum of Variations in Figure 6 is the weekly average of daily bed occupancies. The explanation for oscillations in Plots 3 and 4 in Figure 6 is due to the fluctuations in admission numbers when low volume clinicians are removed as in Figure 3.

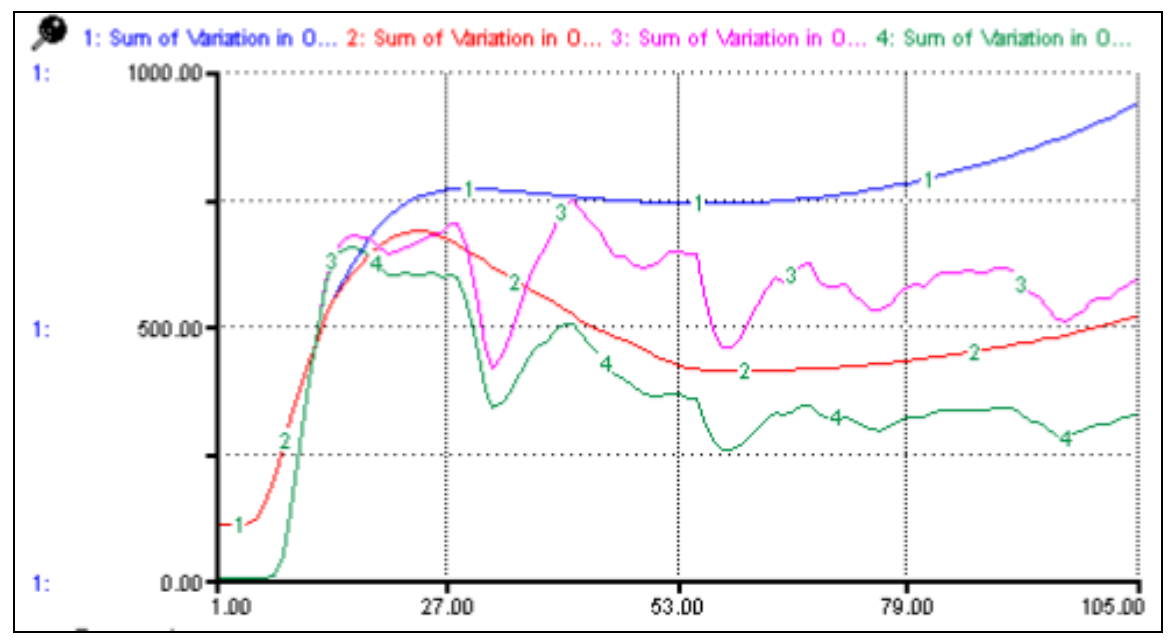

(Plot 1 - No CP implemented; Plot 2- CP implemented; Plot 3- No CP implemented but with reduction of low volume clinicians in DRG G45B; Plot 4 -

CP implemented with a reduction of low volume clinicians in DRG G45B)

Figure 6: Clinical Pathways Policy - Variations in Bed Occupancy in \% (G45B= Gastroscopy)

The quality of care is measured on a relative qualitative scale from $0-1$, where 1 is the most desired outcome for quality. Its importance in the simulation modeling process is to help hospital executives assess the values of quality in relation to each other across different model iterations A notable and desirable consequence of the $\mathrm{CP}$ implementation is the increase in quality of care, even though it is delayed until week 82 (Figure 7; Plot 4) The delayed effect of the CP on quality was explained by hospital executives as a latent result of the reduction of errors in diagnosis and treatment due to implementation of CP being monitored. The full implementation of CP is the result of organizational and cultural changes in attitudes on the part of clinicians and nurses, with greater due diligence in patient management and care. 
A study to determine the effects of clinical pathway implementation on patients undergoing elective pancreaticoduodenectomy (PD) on cost and resource utilization concluded that the establishment of a clinical pathway for PD patients dramatically reduced costs and resource utilization. It had no apparent detrimental effect on quality of patient care. These current findings support the implementation of clinical pathways for PD patients, as well as investigation into pathway care for other complex surgical procedures. (Porter et al, 2000). The evidence of these latter findings is consistent and supports our CP model simulation studies.

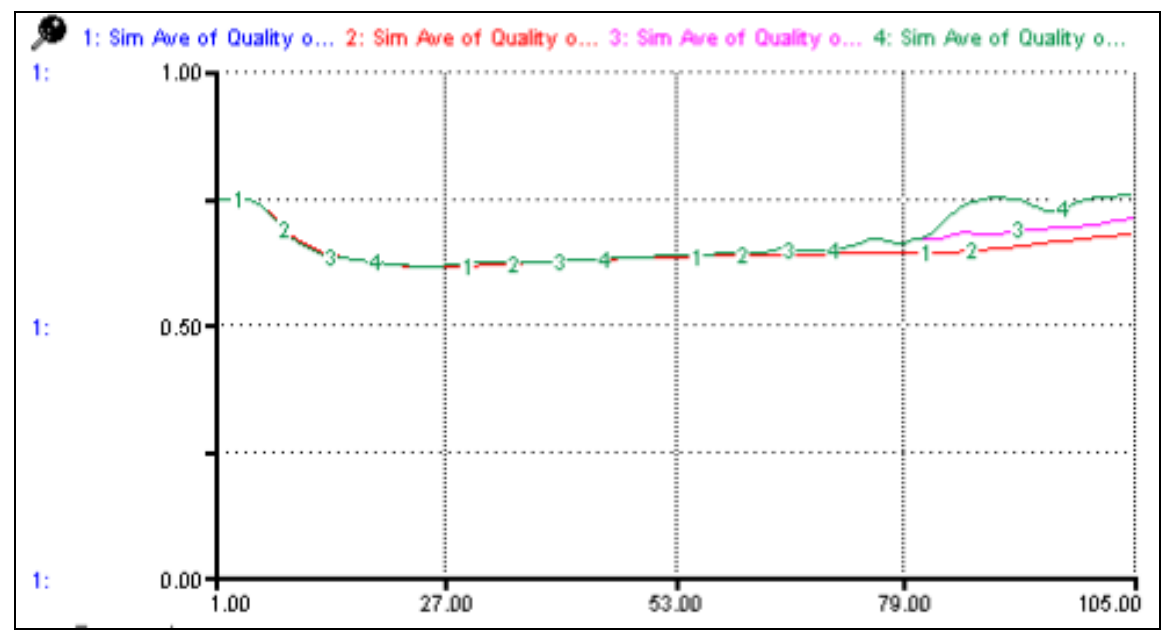

(Plot 1 - No CP implemented Plot 2- CP implemented; Plot 3- No CP implemented but with reduction of low volume clinicians in DRG G45B; Plot 4 -

CP implemented with reduction of low volume clinicians in DRG G45B)

Figure 7: Clinical Pathways Policy - Quality of Care (DRG G45B= Gastroscopy)

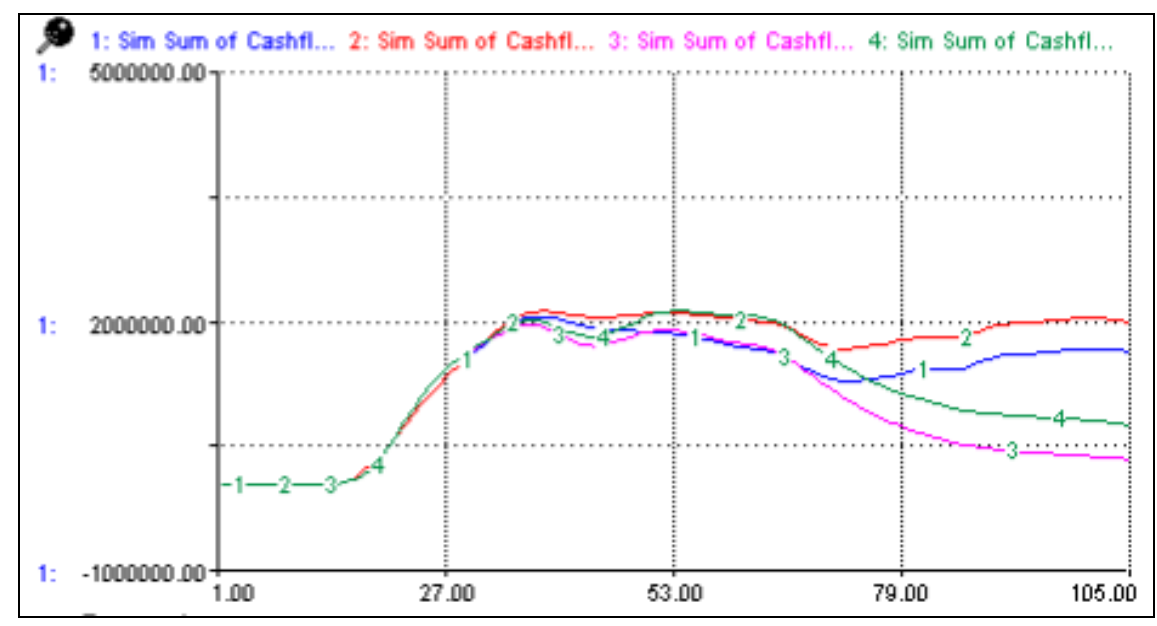

(Plot 1 - No CP implemented; Plot 2- CP implemented; Plot 3- No CP

implemented but with reduction of low volume clinicians in DRG G45B; Plot 4 -

CP implemented with reduction of low volume clinicians in DRG G45B)

Figure 8: Clinical Pathways Policy - Hospital Cashflow (DRG G45B= Gastroscopy) Units= AUD\$

Finally, the CP implementation results in an increase in cashflow less the cost of CP implementation (Figure 8). The main driver for this is the "revolving door" effect that allows more patients to be admitted and treated due to the faster turnaround by the hospital. The comparison of plots $1 \& 2$ with plots $3 \& 4$ 
separately in Figure 8 merely reflects that the reductions in low volume clinicians for DRG G45B did not have any significant impact on cashflow since their patient volume is low.

\section{Discussion}

The lessons for clinicians, which is supported with simulation and interview results, suggest that factors such as the excessive specialization, the lack of flexibility between medical teams, the absence of champions supporting systematic clinical pathways and the level of integration between nursing and medicine are likely to cause serious disruptions to hospital performance. Clinicians agreed that there was currently little evidence of multi-disciplinary clinical production-focused teams at the hospital. The absence of a clinical production focus as a key building block for hospital management and the pre-occupation with input management at all levels are potential areas for clinicians to co-operate with hospital managers.

Clinicians also agreed that the untoward dispersion of patients across multiple wards; the individualism of their profession; the marginality of nursing perspectives in the organization and management of clinical work; and the absence of structures, practices and processes (at the clinician level) oriented to bringing clinical work under control such as clinical pathways needed attention. The lessons learned suggest that clinicians be allowed to participate in operating assumptions, admissions and utilization forecasts, financial performance, return-on investment calculations, governance and organization, marketing and promotion plans, implementation of strategic initiatives and share responsibilities.

Capitation and other risk models of reimbursement change the focus of strategic hospital management from patient admissions to "managing clinical resources". Clinical resource management represents the ability to reduce the cost per episode in line with competitors. Clinical governance as explicitly addressed in the simulation models means providing quality patient care with the least amount of resources. It means not only continuing to reduce length of stay, medical deviations and errors, but also reducing use of ancillary services while the patients are in hospital.

In 2003, a study on the effectiveness of CP in the management of Congestive Heart Failure (CHF) concluded that "the clinical pathway for CHF was associated with increased use of ACE inhibitors and it resulted in a reduced length of stay and hospital charges" (Ranjan, 2003)

Also our simulation model findings on cost and quality improvements associated with CP have been validated independently in a study at Department of Neurosurgery, University of Duisburg-Essen and their conclusions are stated as follows: "Clinical pathways can merge the interests of people with a medical and an economical background in order to improve treatment quality and to enhance cost-structures of complex treatments. The current data demonstrates that the higher initial expenditure of acquiring a neuronavigation system will be indirectly reimbursed as it decreases the overall treatment costs” (Jung et.al, 2007)

The importance and significance of clinical pathways has been emphasised in this study. The hospital has to be selective in developing critical pathways (standard protocols) for treatment of high volume DRG's. The development of clinician practice profiles or signatures that identify how the major specialty groups are performing on the basis of their length of stay and cost per discharge, benchmarked against outcomes compared to peers, other facilities in the market and to national databases, is a vital lesson for policy makers. The same clinical data can be used to create a global contracting model for key services, such as hip replacement, open-heart surgery, stroke management, and other services common to a hospital. Hospital policy makers can apply these non-traditional polices amongst the profession to enhance revenue and reduce low DRG volume clinicians. In a more recent publication Cardoen and Demeulemeester (2007) reveal that a discrete event simulation model the research team developed was deployed in hospitals in Antwerp. It enabled the health manager to evaluate and improve performance indicators such as capacity of, and patient flow along, clinical pathways, to the benefit of both the patient and the hospital.

The hospital can use the simulation model to create "DRG based profitability analysis" that identifies those inpatient and out- patient services with positive and negative bottom lines. Policy makers can then plan for program elimination, subsidization, or expansion based on shared inputs from clinicians. 


\section{Conclusions}

The study has shown that a system dynamics based decision support tool was instrumental in enabling hospital managers and clinicians jointly to review the possibilities for implementation of clinical pathways. Streamlining the clinical practices with appropriate clinical pathways amongst the high volume DRG's will reduce treatment costs significantly. But introducing these without dealing with critical inefficiencies such as low-volume DRG's is not recommended. The casemix simulation model suggests that the hospital management should refine the admitting rights policy to replace "low volume” and multiple DRG's clinicians with "high volume DRG's" clinicians in conjunction with the implementation of clinical pathways. If this is not accomplished then the larger number of clinicians involved dissipates the effort of the clinical pathways policy to streamline clinical practices.

\section{References}

Cardoen, B and Demeulemeester, E., (2007). "Evaluating the Capacity of Clinical Pathways through Discrete-Event Simulation", KU Leuven Department of Decision Sciences and Information Management Working Paper No. KBI 0712 Available at SSRN: http://ssrn.com/abstract=1093290

Chalmers, I. (1993): The Cochrane Collaboration: Preparing, Maintaining and Disseminating Systematic Reviews of the Effects of Health Care, In Warren, K.S. and Mosteller, F. (eds.): Doing More Good Than Harm: The Evaluation of Health Care Interventions, Annals of the New York Academy of Sciences.

Dickinson, R.A., Thomas, S. M. and Naughton, B.B. (1999). Rethinking specialist integration strategies. Journal of Healthcare Financial Management Association, Vol. 53(1). 42-47, Westchester, Jan 1999.

Ellrodt, A.G., Conner, L., Riedinger, M., Weingarten, S. (1995). Measuring and improving clinician compliance with clinical practice guidelines. Annals of International Medicine. 122, 277-282.

Guadagnino, C. (1998). Does standardization equal quality? Physician’s News Digest (Issue April 1998).

Hindle, D. (1998). Classifying the care needs and services received by Home and Community Care (HACC) clients, Aged and Community Care Service Development and Evaluation Reports, Commonwealth Dept. of Health and Family Services, April 1998 -No: 33.

Holt, P., Wilson, A., Ward, J. (1996). Clinical Practice Guidelines and Critical Pathways: A Status Report on National and NSW Development and Implementation Activity. NSW Health Department: Sydney.

Jordens, C.F.C., Hawe, P., Irwig, L.M., Henderson-Smart, D.J., Ryan, M., Donoghue, D.A., Gabb, R.G. and Fraser, I.S. (1998): Use of Systematic Review of Randomised Trials by Australian Neonatologists and Obstetricians, Medical Journal of Australia, March 16.

Jung, M., Böchers, K; Wasem, J.; Stolke, D.;Gasser,T. (2007). Improvement in quality - reduction of costs: clinical pathways prove cost-effectiveness of neuronavigation, Deutsche Gesellschaft für Neurochirurgie. 58. Jahrestagung der Deutschen Gesellschaft für Neurochirurgie e.V. (DGNC). Leipzig, 26.-29.04.2007. Düsseldorf: German Medical Science GMS Publishing House; 2007. Doc P 022,

Leape, L.L. (1990). Practice guidelines and standards: An Overview. Quality Review Bulletin. 42-49 February.

Lomas, J (1989). Do Practice Guidelines Guide Practice?. New England Journal of Medicine. 321, 13061311.

Lugon, M., Secker-Walker,J. (eds). (1999). Clinical Governance: Making it Happen. London: Royal Society of Medicine Press.

Maliapen, M. (1998a). Visual Interactive Modeling, Proceedings of $16^{\text {th }}$ International System Dynamics Conference, Quebec, Canada, July 1998. 
Porter, G.A.; Pisters, P.W.T.; Mansyur, C.; Bisanz, A.,Reyna, K.; Stanford, P.;Jeffrey E. L.; Evans, D.B.(2000) Cost and Utilization Impact of a Clinical Pathway for Patients Undergoing Pancreaticoduodenectomy, Annals of Surgical Oncology, 7(7):484-489

Phillips, P.A. (1998): Disseminating and Applying the Best Evidence, Medical Journal of Australia, March 16.

Ranjan, A. (2003). Effectiveness of the clinical pathway in the management of congestive heart failure, Southern Medical Journal, July, 2003

Saeed, K. (1998). Defining a problem or constructing a reference mode. Proceedings of 16th System Dynamics Conference, Quebec, Canada, 1998.

Scally, G., Donaldson, J. (1998). Clinical Governance and the drive for quality improvement. New NHS in England, British Medical Journal, 317, 61-65.

Secretary of State for Health. (1997). The New NHS. London: Stationery Office (Cmd 3807).

Sterman, J. (2000). Business Dynamics: Systems Thinking and Modeling for a Complex World Irwin/McGraw-Hill, New York.

Thomson, R., Lavender,M., Madhok, R. (1995). How to ensure that guidelines are effective. British Journal of Medicine, 311, 237-242, 22 July.

Vissers J and Beech R (2005). Health Operations Management. London: Routledge 